ESTIMATION OF INPUT-OUTPUT COEFFICIENTS USING NEOCLASSICAL PRODUCTION THEORY

Christian Lager and wolfgang Schopp

February 1985

WP- $85-7$

Presented at the 5 th Task Force Meeting on Input-Output Modeling, IIASA, October $4-6,1984$

Working Papers are interim reports on work of the International Institute for Applied Systems Analysis and have received only limited review. Views or opinions expressed herein do not necessarily represent those of the Institute or of its National Member Organizations.

INTERNATIONAL INSTITUTE FOR APPLIED SYSTEMS ANALYSIS A-2361 Laxenburg, Austria 
PREFACE

Many of today's most significant socioeconomic problems, such as slower economic growth, the decline of some established industries, and shifts in patterns of foreign trade, are interor transnational in nature. But tnese problems manitest themselves in a variety of ways; both the intensities and the perceptions of the problems differ from one country to another, so that intercountry comparative analyses of recent historical developments are necessary. Through these analyses we attempt to identify the underlying processes of economic structural change and formulate useful hypotheses concerning future developments. Our research concentrates primarily on the empiricial analysis of interregional and intertemporal economic structural change, on the sources of and constraints on economic growth, on problems arising from changing patterns of international trade, resource availability, and technology.

The aim of this paper, which was presented at the last Input-Output Modeling Task Force Meeting and is theretore limited to 11 pages, was to combine well-known theoretical approaches from the theory of production and to apply them to a data base drawn up within the framework of modern inputoutput statistics. The changes in I/O coefficients observed for the Canadian basic metal industry are attributed to changes in microtechnologies brought about by shifts in the relative prices and the output structure of this industry.

Anatoli Smyshlyaev

Project Leader

Comparative Analysis of

Economic Structure and Growth 


\title{
Estimation of Input-Output Coefficients Using Neoclassical Production Theory
}

\author{
Christian Lager and Wolfgang Schöpp \\ International Institute for Applied Systems Analysis, Laxenburg, Austria.
}

\section{INTRODUCTION}

Over the years there has been much research and investigation into the question of change in input-output (IO) coeffients, which lie at the heart of any IO model. This research has taken many productive directions. Besides technical progress, two main reasons for changes in IO coefficients have been identified:

- Input factor substitution (including substitution of domestic products by imported commodities) caused by changes in the input price system (price effects), and

- Changing output structures of the industries concerned (product-mix effects).

An extensive literature exists on price effects: Tilanus (1966) concluded that the classical assumption of IO analysis, namely that value coefficients are constants, is less workable than the hypothesis that value coefficients (cost shares) are stable. Klein (1952) proved that this hypothesis requires a multiproduct Cobb-Douglas function. Using recent production theory, much more flexible assumptions were used by Frenger (1978), Bonnici (1983), Nakamura (1984), and Andersson et al. (1984), by applying Diewert (generalized Leontief) production or cost functions to IO data. Frenger (1978) analyzed the price-responsiveness of 10 coefficients for textiles, construction, and metals and concluded that "there would seem to be little doubt that the Leontief assumption would have to be rejected ... relative prices have a significant effect on the viability of IO coefficients". Bonnici (1983) estimated a complete set of price-dependent IO coefficients derived from corresponding Diewert cost functions for all 17 sectors covered by a time series of annual IO tables. A comparison of the traditional method (forecasting on the basis of the coefficients from the most recent year available) with the generalized Leontief model showed that "... the forecasts of the generalized Leontief model outperform those of the (common) IO model in two out of every three cases". Cortrary to Tilanus, Bonnici concluded that, whenever a time series of IO tables is available, there is considerable scope for relaxing the somewhat rigid assumption of fixed IO coefficients.

Another body of literature is devoted to product-mix effects. Here, the idea is that changes in the input coefficients of aggregate industries are attributable to changes in the industries' internal output profiles rather than to shifts caused by changes in the production processes.

Sevaldson (1960) wrote in the introduction to the 1954 Norwegian IO tables: "Lack of sector homogeneity makes product mix the dominant source of changes in the coefficients". A cross-sectional analysis on an establishment level by Forssell (1969), for six fairly homogeneous industry groups, showed that two-thirds of the explained dispersion of input coefficients among establishments could be attributed to heterogeneity in commodity mix while just one-third was found to be due to replacement of particular inputs by other commodities. Lager (1983) analyzed the changes in the energy coefficients of five of the most energy-intensive sectors in Austria and found that explicit consideration of product-mix effects produced a significant decline in the price elasticities. This result might encourage the assumption that changes in the input price system lead not only to changes in the 
(micro)technologies involved but also to remarkable effects on the output structure, and therefore that they contribute in tro ways to changes in the technical coefficients of industry groups. However, it is generally agreed that changes in technology as well as shifts in production structure have explanatory power for estimating changes in the input coefflcients. Consequently, emphasis on productmix effects leads to rather large 10 tables and disaggregated, but simple, models. On the other hand, the introduction of factor substitution implies flexible production functions and more or less aggregated, but complicated, modeling.

\section{GENERAL CONSTDERATIONS}

The aim of this study is to contribute to this "trade off" in such a way that both product-mix effects and factor substitution caused by changes in prices can play a role in explaining shifts in IO coefficients. This approach has been supported and stimulated by recent developments in the availability and structure of IO statistics: more and more IO tables are now compiled according to the concepts of the System of National Accounts (SNA) 1968 (UN 1968). Industrial interactions are described by two matrices: the make matrix shows the production of commodities by industries while the use matrix shows the demand of industries by commodities. The demand of an industry for a certain commodity $\left(x_{i}\right)$ can be specified as

$$
x_{i}=\sum_{k} a_{i k} \cdot Q_{k}
$$

where $Q_{k}$ is the volume (value at constant prices) of commodity $k$ produced in that industry and $\sigma_{u k}$ is the input coefficient, which specifies the requirement of input $i$ for output $k$.

If we assume that the input coefflcients $a_{i k}$ are functions of the input price indices $p=\left(p_{1}, p_{2}, \ldots, p_{n}\right)$, we can relate the changes in the industrial input requirements to changes in the price system and to changes in the production structure:

$$
x_{i}=\sum_{k} a_{u k}(p) \cdot Q_{k}
$$

If we choose a flexible functional form for the input coeffleients $Q_{u k}(p)$ that allows for changes in the substitution elasticities, we would soon have problems associated with the estimation of too many parameters. A typical problem with the estimation of a sophisticated production function is that the observations are frequently not well distributed over the complete possibility set, but are grouped in clumps close together. This makes it very difficult to distinguish between different functionai forms. Statistically speaking, one must also be very careful with the number of degrees of freedom assigned to a given problem, and it should be remembered that it is hard to separate very similar effects by using statistical analysis.

Therefore, following recent production theory, will define a multiinput/multi-cutput technology for a whole industry and then try to derive micro demand functions for single commodities.

Suppose that an industry faces a series of competitive input markets with given input prices $\left[p=\left(p_{1}, p_{2}, \ldots, p_{n}\right)\right]$. Suppose further that there exists a technologically determined input requirement set that determines inputs for each exogenously determined (e.g. by demand, capacity) set of producible outputs $\left[Q=\left(Q_{1}, Q_{2}, \ldots, Q_{m}\right)\right]$. The cost function ${ }^{1}$ for the industry is then defined by

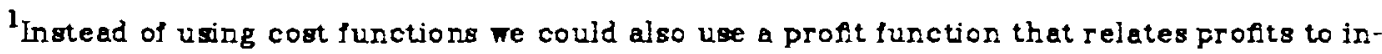
put as rell as output prices.
} 


$$
\begin{gathered}
-3- \\
C=C(p, Q)
\end{gathered}
$$

and specifies the least cost of producing the output bundle $Q$ at given input prices p. (For the sake of simplicity, technical progress is ignored here.)

Further, we assume that the technology used for a single product is in no sense related to the production processes for other commodities produced in the same industry. For example, the input requirements for steel products do not depend on the quantity of aluminum produced in the same industry. Therefore, for any individual output $Q_{k}$, a separable, non-joint, single-output cost function can be specified:

$$
C_{k}=C_{k}\left(p, Q_{k}\right)
$$

The total cost of production is then simply

$$
C=\sum_{k} C_{k}\left(p, Q_{k}\right)
$$

In addition, we assume linear homogeneity for all commodity cost functions and therefore

$$
C=\sum_{k} g_{k}(p) \cdot Q_{k}
$$

Using Shephard's Lemma, $x_{\imath}=\partial C / \partial p_{1}$, we obtain again

$$
x_{i}=\sum_{k} \alpha_{k k}(p) \cdot Q_{k}
$$

where

$$
a_{i j}(p)=\frac{\partial g_{k}(p)}{\partial p_{i}}
$$

Therefore, the input coefficients for a multi-product technology can be derived from a linear-homogeneous, non-joint cost function:

$$
\alpha_{i k}(p)=\frac{\partial^{2} C(p, Q)}{\partial q_{k} \partial p_{i}}
$$

\section{THE TRANSLOG COST FUNCTION WITH LINEAR HONOGENETTY IN THE INPUT PRICES AND CONSTANT RETURNS TO SCALE}

To test the restrictions described in Section 2 we start with a more general approach. Thus, we define a production possibility frontier that does not imply nonjointness or constant returns to scale a priori, but that does enable us to apply statistical tests to these restrictions. For this purpose we choose the translog function introduced by Christenson et al. (1973), which is a second-order approximation of any function.

We approximate the cost function at $p_{\mathfrak{l}}=1, Q_{t}=1$ by:

$$
\begin{aligned}
\ln (C) & =a_{0}+\sum_{i=1}^{i=n} \alpha_{i} \ln \left(p_{i}\right)+\sum_{k=1}^{k=m} \beta_{k} \ln \left(Q_{k}\right)+\frac{1}{2} \sum_{i=1}^{i=n} \sum_{j=1}^{j=n} \gamma_{i j} \ln \left(p_{i}\right) \ln \left(p_{j}\right) \\
& +\frac{1}{2} \sum_{k=1}^{k=m} \sum_{i=1}^{i=m} \vartheta_{k} \ln \left(Q_{k}\right) \ln \left(Q_{i}\right)+\sum_{i=1}^{i=n} \sum_{k=1}^{k=m} \delta_{i k} \ln \left(p_{i}\right) \ln \left(Q_{k}\right)
\end{aligned}
$$

The parameters of the translog function equal the first- and second-order 
derivatives at the point of expansion:

$$
\begin{gathered}
\alpha_{0}=\ln C_{0}, \alpha_{i}=\frac{\partial \ln C}{\partial \ln p_{i}}, \beta_{k}=\frac{\partial \ln C}{\partial \ln Q_{k}} \\
\gamma_{i j}=\frac{\partial^{\mathbb{R}} \ln C}{\partial \ln p_{i} \partial \ln p_{i}}, v_{k l}=\frac{\partial^{2} \ln C}{\partial \ln Q_{k} \partial \ln Q_{l}}, \delta_{v k}=\frac{\partial^{\mathbb{2}} \ln C}{\partial \ln p_{i} \partial \ln Q_{k}}
\end{gathered}
$$

Symmetry of the second-order derivatives requires that $\gamma_{k j}=\gamma_{t i}$ and $\vartheta_{k t}=\vartheta_{k k}$.

One usual condition for a cost function is linear homogeneity in input prices. It is easy to prove that this requires that

$$
\sum_{i=1}^{i=n} a_{i}=1, \sum_{i=1}^{i=n} \gamma_{t j}=0, \sum_{k=1}^{k=m} \delta_{i k}=0 .
$$

Constant returns to scale requires linear homogeneity in the outputs. Thus, taking the symmetry restriction and linear homogeneity into account, we obtain an additional set of restrictions:

$$
\sum_{k=1}^{k=m} \beta_{k}=1, \sum_{k=1}^{k=m} \vartheta_{k l}=0, \sum_{k=1}^{i=n} \delta_{k k}=0
$$

and

$$
\sum_{i=1}^{j=n} \gamma_{i j}=0, \sum_{l=1}^{l=m} v_{k l}=0
$$

\section{NON-JOINTNESS RESTRICTION ON THE TRANSTOG COST FUNCTION}

As described in Section 2, non-joint production requires a cost function of the type:

$$
C=\sum_{k} C_{k}\left(p, Q_{k}\right)
$$

Consider the first- and second-order derivatives of this general non-joint cost function:

$$
\begin{gathered}
\frac{\partial \ln C}{\partial \ln Q_{k}}=\frac{1}{C} \frac{\partial C_{k}}{\partial \ln Q_{k}}, \quad k=1,2, \ldots, m, \\
\frac{\partial^{2} \ln C}{\partial \ln Q_{k} \cdot \partial \ln Q_{l}}=-\frac{1}{C^{2}} \frac{\partial C_{k}}{\partial \ln Q_{k}} \frac{\partial C_{l}}{\partial \ln Q_{l}}, \quad k \neq l, k, l=1,2, \ldots, m .
\end{gathered}
$$

The first- and second-order derivatives of $\ln C$ equal the parameters $\beta_{k}$ and $v_{k l}$ at the point of expansion. Consequently, non-jointness requires

$$
\vartheta_{k l}=-\beta_{k} \cdot \beta_{i} \text { for all } k, l, k \neq l \text {. }
$$

As described above, the translog function is a second-order approximation of the cost function at a point of expansion. Consequently, this restriction defines nonjointness only around that point of expansion. 


\section{HOW TO ESTILATE THE TRANSLOG COST FUNCTION}

Using Shephard's Lemma we obtain a system of $n$ cost-share equations

$$
s_{i}=\frac{\partial \ln C}{\partial \ln p_{i}}=\alpha_{i}+\sum_{j=1}^{1=n} \gamma_{j} \ln \left(p_{j}\right)+\sum_{k=1}^{k=m} \delta_{k k} \ln \left(Q_{k}\right)
$$

where

$$
s_{i}=P_{i} \frac{X_{i}}{C}
$$

The use of the share equations makes it possible to justify the parameter restrictions that arise from the imposition of linear homogeneity. Since the sum of all the shares must be one, and the linear homogeneity and symmetry constraints are used, only $n-1$ equations remain to be estimated. The last equation depends on the others, and must be calculated from them.

The share equations described above do nct permit the estimation of the complete cost function. In order to estimate the parameters $\vartheta_{k l}$ and $\beta_{k}$, we need to define additional equations. The cost function itself can be used to get the missing parameters. The other way out is to specify an output price rule.

If we assume that the manufacture of each product breaks even, we can relate total costs to total outputs, $C_{k}=p_{k} Q_{k}$. Therefore the nominal product-mix coefflcient is defined as $v_{k}=C_{k} / C$.

Non-jointness requires that

$$
\frac{\partial \ln C}{\partial \ln Q_{k}}=\frac{1}{C} \frac{\partial C_{k}}{\partial \ln Q_{k}}=\frac{C_{k}}{C} \frac{\partial \ln C_{k}}{\partial \ln Q_{k}}
$$

Constant returns to scale in the micro cost function $C_{k}$ yields

$$
\frac{\partial \ln C_{k}}{\partial \ln Q_{\mathbf{k}}}=1
$$

Consequently,

$$
\frac{\partial \ln C}{\partial \ln Q_{k}}=\frac{C_{k}}{C} \equiv v_{k}
$$

This enables us to define an additional, estimatable set of $m$ nominal product-mix equations, which now include the parameters $\vartheta_{k l}$ and $\beta_{k}$ :

$$
v_{k} \equiv \frac{C_{k}}{C}=\beta_{k}+\sum_{i=1}^{l=m} v_{k l} \ln q_{l}+\sum_{i=1}^{i=n} \delta_{l k} \ln p_{i}
$$

From the nominal product-mix equations $v_{k}$ we obtair micro cost functions $C_{k}$. Applying Shephard's Lemma, we can devise demand equations for each single output $\boldsymbol{k}$ :

$$
x_{i k}=\frac{C}{p_{i}}\left[\delta_{i k}+v_{k} \cdot s_{i}\right] .
$$

Dividing $x_{i k}$ by $Q_{k}$, we can obtain commodity-by-commodity 10 coefficients. 


\section{PRICE AND SUBSTITUTION RIASTICTTTES}

Here we begin by defining the price elasticity of input demand as the percentage change in input $x_{i}$ when the input price $p_{j}$ changes by one percent

$$
\begin{gathered}
\varepsilon_{i j}=\frac{\partial \ln \left(x_{i}\right)}{\partial \ln \left(p_{j}\right)} . \\
Q=\text { constant, } p_{i}=\text { constant, for } i \neq j .
\end{gathered}
$$

Next, the Allen elasticities of substitution are defined as follows:

$$
\sigma_{i j}^{A}=\frac{C \cdot C_{i j}}{C_{i} \cdot C_{j}}, C_{i}=\frac{\partial C}{\partial p_{i}}, C_{i j}=\frac{\partial^{2} C}{\partial p_{i} \partial p_{j}}
$$

The Allen elasticities are symmetric, $\sigma_{i j}^{A}=\sigma_{\mathcal{H}}^{A}$.

Using Shephard's Lemma, a relation can be obtained between the Allen elasticities and the price elasticities:

$$
s_{i} \cdot \sigma_{i j}^{A}=s_{i} \cdot \frac{C\left(\partial x_{i} / \partial p_{j}\right)}{x_{i} x_{j}}=\frac{\left(\partial x_{i} / \partial p_{j}\right)}{\left(x_{i} / p_{j}\right)}=\varepsilon_{i j}
$$

One of the major advantages of the translog function is that the elasticities $\varepsilon_{i j}$ and $\sigma_{i j}$ are not, a priori, constant but depend on the cost shares. To obtain the explicit derivation, it is best to compute the Allen elasticities first. The use of the translog cost function yields:

$$
\sigma_{i j}^{A}= \begin{cases}\frac{\gamma_{i j}+s_{i} s_{j}}{s_{i} s_{j}} & \text { for } i \neq j \\ \frac{\gamma_{i i}+s_{i}^{2}-s_{i}}{s_{i}^{2}} & \text { for } i=j\end{cases}
$$

Having computed the Allen elasticities, the fundamental relation shown above can be used to obtain the price and substitution elasticities:

$$
\varepsilon_{i j}=s_{i} \sigma_{i j}^{A}= \begin{cases}\frac{\gamma_{i j}+s_{i} s_{j}}{s_{j}} & \text { for } i \neq j \\ \frac{\gamma_{i j}+s_{i}^{2}-s_{i}}{s_{i}} & \text { for } i=j\end{cases}
$$

Assuming a multi-product industry sector, we can also explain the effects of a change in the product mix. For this purpose we define an input/output elasticity $\theta_{i k}$, which tells us what happens to the input $x_{i}$ if the output $Q_{t}$ changes:

$$
\begin{aligned}
\otimes_{i k} & =\frac{\partial \ln x_{i}}{\partial \ln Q_{k}} \\
p=\text { constant, } Q_{l} & =\text { constant, for } l \neq k .
\end{aligned}
$$

We will calculate the input/output elasticities $\Theta_{i k}$ from the $i$ th cost share:

$$
s_{i}=\alpha_{i}+\sum_{j=1}^{j=n} \gamma_{i j} \ln p_{j}+\sum_{k=1}^{k=m} \delta_{i k} \ln Q_{k}
$$

Use of the cost shares then yields: 


$$
\frac{\partial x_{i}}{\partial \ln Q_{k}}=\frac{\delta_{i k}}{s_{i}}+\frac{\partial \ln C}{\partial \ln Q_{k}}=\frac{\delta_{i k}}{s_{i}}+\beta_{k}+\sum_{j=1}^{i=n} \delta_{j k} \ln p_{j}+\sum_{l=1}^{l=m} \vartheta_{l k} \ln Q_{l} .
$$

\section{APPLICATION TO A REAL DATA SET: PREIIMINARY RESULTS}

The approach described in the preceding sections has been applied to a series of make and use tables for the Canadian economy covering the period 1961-1978. The data are expressed in terms of both actual and constant 1971 dollar producer prices and were supplied by Statistics Canada. We utilized the M (medium) aggregation level, in which these rectangular tables are classified into 43 industries and 92 commodities. The approach described below was applied to the "primary metal" industry. The outputs were aggregated into three commodities, as shown in Table 1 , while the six inputs shown in Table 2 were distinguished.

TABLE 1. Outputs of the Canadian basic metal industries in 1971.

\begin{tabular}{lcr}
\hline \hline Output & $10^{6}$ Dollars & \% of total \\
\hline Iron and steel & 2019.4 & 39.5 \\
Nonferrous metals & 2587.7 & 50.5 \\
Other & 512.0 & 10.0 \\
Total & 5119.1 & 100.0 \\
\hline \hline
\end{tabular}

TABLE 2. Inputs into the Canadian basic metal industries in 1971.

\begin{tabular}{lrr}
\hline \hline Input & $10^{6}$ Dollars & $\%$ of total \\
\hline Iron ores and concentrates & 151.1 & 3.0 \\
Other metal ores and concentrates & 1284.5 & 25.1 \\
Energy & 265.9 & 5.2 \\
Basic metal products & 879.2 & 17.2 \\
Other inputs (including margins, indirect taxes) & 918.2 & 17.8 \\
GDP at factor costs & 1620.2 & 31.6 \\
Total & 5119.1 & 100.0 \\
\hline \hline
\end{tabular}

For each of these six inputs a producer price index ${ }^{2}$ was calculated.

The results of the analysis presented in this section are rather preliminary in nature: the significance of the elasticities has not yet been tested and therefore caution should be exercized with any interpretation of the results.

Table 3 presents a second-order approximation of the commodity-by-commodity IO coefflcients for the base year (1971).

We restricted nonferrous ore input to basic ferrous products and ferrous ore input to basic nonferrous products. The input coeflcients for "other inputs" are calculated as a residuai. With relatively few exceptions, the estimates for the commodity-by-commodity coefficients seem to be reasonable: all negative coefficients are insignificant, and steel production requires much more energy per

\footnotetext{
${ }^{2}$ For this preliminary report no attermt was made to calculate margins or indirect taxes on the commodity inputs so thet purchesers' price indexes could be derived.
} 
TABLE 3. Approximation of commodity-by-commodity IO coefficients for the Canadian basic metal industries in 1971 ( $t$-values in parentheses).

\begin{tabular}{lccc}
\hline \hline Input & $\begin{array}{c}- \\
\text { Iron and steel } \\
\text { products }\end{array}$ & $\begin{array}{c}\text { Output } \\
\text { Nonferrous metal } \\
\text { products }\end{array}$ & $\begin{array}{c}\text { Other } \\
\text { products }\end{array}$ \\
\hline Iron ores & 0.056 & 0 & 0.067 \\
Nonferrous ores & $(7.6)$ & 0.540 & $(2.6)$ \\
Energy & 0 & $(13.8)$ & -0.179 \\
Metal products & 0.126 & 0.023 & $(1.0)$ \\
GDP at factor costs & $(6.2)$ & $(1.1)$ & -0.029 \\
& 0.274 & -0.058 & $0.4)$ \\
Other inputs & $(7.1)$ & $(1.6)$ & $(5.1)$ \\
\hline \hline
\end{tabular}

unit of output (value) than does the production of nonferrous metals. Statistics Canada (1978) reported that, in Canada in 1971, 209 GJ was required per 10008 worth of output of the iron and steel industries, while for the aluminum or copper industries the corresponding values were $163 \mathrm{GJ}$ and $8 \mathrm{GJ}$, respectively.

As nonferrous ores are much more expensive than iron ores, the high nonferrous-ore input coefflcient and the correspondingly small iron-ore coefficients seem reasonable. On the other hand, it is not reasonable that the production of "other products" should require more ferrous ores than does basic ferrous metal production. No attempt has been made to estimate a time series of commodity-bycommodity IO coeffcients.

The influence of prices and changing output structures on the input requirements of the basic metal industries is demonstrated by a set of the relevant elasticities. To begin with, the symmetric Allen elasticities of substitution are presented in Table 4.

TABLE 4. Allen elasticities of substitution for the Canadian basic metal industries in 1977 .

\begin{tabular}{lccccr}
\hline \hline & $\begin{array}{c}\text { Nonferrous } \\
\text { ores }\end{array}$ & Energy & $\begin{array}{c}\text { Metal } \\
\text { products }\end{array}$ & $\begin{array}{c}\text { Other } \\
\text { inputs }\end{array}$ & $\begin{array}{r}\text { Value } \\
\text { added }\end{array}$ \\
\hline Iron ores & 0.042 & 0.009 & -0.003 & -0.078 & 0.226 \\
Nonferrous ores & & 0.001 & -0.170 & -0.104 & -0.044 \\
Energy & & & 0.002 & -0.012 & 0.138 \\
Metal products & & & & 0.051 \\
Other inputs & & & & 0.087 \\
\hline \hline
\end{tabular}

No large elasticities of substitution were found, thus indicating that relative prices have only a small impact on input relations. GDP is found to be a partial substitute for ores and for energy. As might be expected, metal products are not substitutes for energy or ores, but are complementary to nonferrous ores. It seems reasonable that all inputs (trade and transport margins, taxes, overheads) are complementary to most of the inputs. 
Own-price elasticities were calculated for all of the inputs. For energy, GDP, ferrous ores, and other inputs, negative elasticities were found. Table 5 presents a time series of own-price elasticities and Allen elasticities of substitution for energy and GDP expressed in terms of value added.

TABLE 5. Own-price elasticities $\left(\varepsilon_{E}, \varepsilon_{V_{A}}\right)$ and Allen elasticities of substitution $\left(\sigma_{B}^{A}, V_{A}\right)$ for energy and GDP (VA) for the Canadian basic metal industries, $1861-1877$.

\begin{tabular}{lccc}
\hline \hline Year & $\varepsilon_{\boldsymbol{E}}$ & $\varepsilon_{V_{A}}$ & $\sigma_{\boldsymbol{E}, V_{A}}$ \\
\hline 1961 & -0.326 & -0.730 & 0.154 \\
1962 & -0.271 & -0.726 & 0.161 \\
1963 & -0.273 & -0.723 & 0.164 \\
1964 & -0.212 & -0.725 & 0.168 \\
1965 & -0.190 & -0.714 & 0.178 \\
1966 & -0.185 & -0.718 & 0.175 \\
1967 & -0.167 & -0.740 & 0.161 \\
1968 & -0.156 & -0.743 & 0.160 \\
1969 & -0.124 & -0.736 & 0.168 \\
1970 & -0.212 & -0.759 & 0.144 \\
1971 & -0.273 & -0.732 & 0.157 \\
1972 & -0.300 & -0.733 & 0.154 \\
1973 & -0.260 & -0.749 & 0.147 \\
1974 & -0.378 & -0.776 & 0.119 \\
1975 & -0.475 & -0.760 & 0.120 \\
1976 & -0.480 & -0.775 & 0.111 \\
1977 & -0.468 & -0.733 & 0.138 \\
\hline \hline
\end{tabular}

A relatively large and constant own-price elasticity, varying smoothly in the region of -0.75 , was found for GDP, indicating that there has been a significant and constant impetus to increase the productivity of primary inputs.

Comparatively smaller own-price elasticities were found for energy, and these varied over time with a characteristic pattern. In the course of the sixties, when real energy prices went down, elasticities moved from $-0.32 \%$ to $-0.12 \%$. In the seventies, when energy became more expensive, the sensitivity of energy use to price grew again noticeably. This is refiected in the growth of the own-price elasticity, wich jumped from -0.26 in 1973 to -0.48 in 1975.

The Allen elasticities of substitution for GDP and energy are rather small. The most surprising result is that, especially from 1971 to 1976 , substitution elasticities fell. In 1977 the Allen elasticities started to increase again. To summarize: pricesensitive changes in the own-price elasticities for energy indicate that rising energy prices are likely to improve energy efficiency, while the relatively small and price-insensitive elasticities of substitution show us that rising energy prices do not stimulate substitution between energy and value added in the short term. The increase in the Allen elasticity noted for 1977 may indicate that there exists a time lag of about three years between a change in energy price and a response in terms of substitution behavior.

Finally, the changes in the inputs resulting from changes in the outputs were analyzed using the 10 elasticities shown in Table 6.

Output elasticities for nonferrous ores varied around 1, indicating that the corresponding IO coefficients are rather stable, while the elasticities for iron ores 
TABLE 6. Selected IO elasticities for the Canadian basic metal sector in 1965,1970 , and 1975.

\begin{tabular}{lcccccc}
\hline \hline Outputs & & - & \multicolumn{2}{c}{ Inputs } & & \\
& Year & Iron ores & NF ores & Energy & Metals & GDP \\
\hline Ferrous & 1965 & 0.767 & 0 & 0.965 & 0.781 & 0.412 \\
metal & 1970 & 0.758 & 0 & 0.919 & 0.772 & 0.387 \\
& 1975 & 0.756 & 0 & 0.766 & 0.788 & 0.452 \\
& & & & & & \\
Non- & 1965 & 0 & 1.105 & 0.153 & -0.206 & 0.566 \\
ferrous & 1970 & 0 & 1.055 & 0.187 & -0.219 & 0.597 \\
metals & 1975 & 0 & 1.109 & 0.245 & -0.204 & 0.517 \\
\hline \hline
\end{tabular}

were somewhat lower at around 0.75 , showing that the iron ores coefficients are not only affected by the output of ferrous metal but also by other factors.

Both the energy and the metal elasticities are different for the two groups of output. Therefore it seems that shifts in product mix influence both the energy and the metal input coefficients for the industry as a whole. The energy elasticities of around 0.9 noted in the sixties and early seventies indicated that the energy/output ratio for ferrous metal was relatively constant, while the declining elasticities since 1975 show again that there have been some attempts to save energy since the first oil shock. The negative elasticities calculated for metals transformed into nonferrous metals output are not significant. 


\section{REFTRRENCES}

Andersson, A., R. Brännlund, and G. Kornai (1984). The Demand for Forest Sector Products. Working Paper WP-84-87. International Institute for Applied Systems Analysis, Laxenburg, Austria.

Bonnici, J. (1983). The relevance of input substitution in the interindustry model. European Economic Review, 22.

Christenson, L.R., D.W. Jorgenson, and L.J. Lau (1973). Transcen dal logarithrnic production frontiers. Review of Economics and Statistics, 55(1).

Forssell, O. (1969). Statistical unit, classification and aggregation in Finnish inputoutput study. In International Comparison of interindustry Data. Industrial Planning and Programming Series, No. 2. United Nations, New York.

Frenger, P. (1978). Factor substitution in the interindustry model and the use of inconsistent aggregation. In M. Fuss and D. McFaddon (Eds.), Production Economics: Approach to Theory and Applications. Vol. 2. North-Holland, Amsterdam.

Klein, L.R. (1952). On the interrelation of Professor Leontief's system. Review of Economic Studies, 20(2).

Lager, C. (1983). Analysis of energy coefficients in Austria, 1964-1980. In A Smyshlyaev (Ed.), Proceedings of the Fourth IIASA Task Force Meeting on Input-Output Modeling. CP-83-S5. International Institute for Applied Systems Analysis, Laxenburg, Austria.

Nakamura, S. (1984). An interindustry translog model of prices and technical change for the West German economy. Lecture Notes in Economics and Mathematical Systems, No. 221.

Sevaldson, P. (1960). Cited in Frenger (1978).

Statistics Canada (1978). Energy Availability, Detailed Disposition and Industrial Demand Coefficients for Canada, 1971.

Tilanus, C.B. (1966). Input-Output Experiments, The Netherlands 1948-1960. Rotterdam University Press, Rotterdam.

UN (1968). A System of National Accounts. United Nations, New York. 